\title{
The investigation of alexithymia in patients with Parkinson disease
}

\author{
Ali Rıza Sonkaya ${ }^{1}$, Mustafa Ceylan ${ }^{2}$ \\ (1) University of Health Sciences, Okmeydani Training and Research Hospital, Department of Neurology, Istanbul, Turkey \\ (2) Atatürk University, Faculty of Medicine, Department of Neurology, Erzurum, Turkey
}

Date submitted:

Jan 11, 2019

Date accepted:

Feb 22, 2019

Online publication date:

September 15, 2019

\section{Corresponding Author: \\ Ali Rıza Sonkaya \\ University of Health Sciences, \\ Okmeydani Training and \\ Research Hospital, Department \\ of Neurology, Istanbul, \\ drsonkay@gmail.com}

Keywords: Parkinson disease, Alexithymia, Non-motor symptoms.

\begin{abstract}
Aims:Parkinson Disease (PD) is a neurodegenerative disorder that is thought to be almost particularly featured by motor symptoms and non-motor symptoms such as sleep problems, cognitive impairments, anxiety, and alexithymia.

Methods:This study was conducted on 67 patients with Idiopathic Parkinson Disease (IPD) between ages 57 and 79 who admitted to the Neurology Clinic in Okmeydani Training and Research Hospital and 70 healthy subjects. All participants had given written consent. Alexithymia status were assessed with Toronto Alexithymia Scale (TAS) respectively.

Results:Our results showed TAS scores were significantly higher in PD group $(p<0.05)$. TAS- 20 scores were found to be higher in patients with IPD whose disease duration was longer than 8 years and it was no significant correlation was found between TAS-20 total score and Levadopa equivalent daily dose (Ledd) ( $p>0.05$ ). Also, our findings showed significant correlation between alexithymia and UPDRS III scores which are higher than 30. One of the novel results in this study that alexithymia was found to be higher in smoked patients with IPD group than non-smoked, but it was not statically significant ( $p$ $>0.05$ ).

Conclusions:The present study suggests that alexithymia may be related with the disease process of IPD and it should be considered in patients with IPD evaluation and management.
\end{abstract}

\section{Introduction}

Parkinson Disease (PD) is a common neurodegenerative disorder that is thought to be almost particularly featured by motor symptoms such as bradykinesia (slow movement), rigidity, resting tremor, postural instability (balance problems), walking/gait problems, and non-motor symptoms like sleep problems, disturbances in the sense of smell, fatigue, urinary problems, sexual problems, autonomic dysfunctions, cognitive impairments, psychosis, speech deficits, mood and anxiety disorders, depression, and alexithymia (1).

Alexithymia, which is defined briefly "without words for emotions" in the literature (2), was the first time defined by Sifneos during the psychodynamic oriented psychotherapy sessions of the patients who had psychosomatic disorders. He indicated that these patients had difficulty in defining, discriminating and putting their feelings and thoughts in words; had limited fantasy worlds and mostly focused on outer world realities than their own feelings during the therapy (3). Alexithymia can therefore be accepted as an inadequacy to identify and to communicate emotions. Since previous researches have demonstrated a high prevalence of this disturbance in patients with $P D$, influence of dysregulation symptoms has been indicated to have a relevant impact on patients with PD $(4,5)$.

Neuropsychiatric symptoms consisting of depression, fatigue, anxiety, cognitive impairment and alterations in personality can be observed in patients with IPD. The most prominent symptom seen in these patients is depression (6). There is various evidence in the literature considering the role of alexithymia in depression (4). Although there are a number of studies reporting a close relationship between alexithymia and depression (5), there is no clear opinion whether these two are distinctive from one another or overlapping. While alexithymia is often associated with depression $(4,5)$, previous research has demonstrated that they should be considered distinct constructs (6). In IPD, some studies also related alexithymia and depression (7), while others showed that the two conditions may be reliably dissociated in this disorder $(8,9)$, suggesting that alexithymia is at least partly independent of depression in IPD and may be directly associated to the disease process (4).

Although, alexithymia has been stated to be a widespread 
neuropsychiatric concomitant of IPD (10), it has still poorly understood. It may be a significant phenomenon in non-motor characteristics of PD. Dopamine depletion in brain areas critical for emotional cognition, such as anterior cingulate cortex and orbitofrontal cortex may underlie the manifestation of alexithymia in this disorder (4). Also, in limited number of studies was indicated a high prevalence of this disturbance in patients with PD $(11,12)$. Because of this literature gap, in this study we aimed to investigate the role of alexithymia in patients with PD.

\section{Methods}

This study was designed as a prospective work (also called a cohort study). 72 patients between ages 57 and 79 who admitted to the Neurology Clinic in Health Science University Okmeydani Training and Research Hospital and were diagnosed with IPD according to Movement Disorder Society criteria for PD (MDSPD) and 70 healthy subjects matched in this study. First, features of participants were entered in demographic data form. All subjects were literate and had given written consent. Patients who declined to attend the study, were not literate, had another diagnosed neurological disease, or had a history of psychoactive substance abuse were excluded from the study. The study was approved by local ethics committee (Protocol no: 48670771-514.10).

In this study alexithymia was assessed by means of the Toronto Alexithymia Scale (TAS-20). TAS-20 is a validated selfreport 20-item questionnaire with a five-point Likert response scale (5). TAS-20 total score of 61 or more is evaluated as alexithymia and if less than 61 is evaluated as non-alexithymia (13). The total score ranges from 20 to 100 and allows subjects to be categorized as "Non-alexithymic" (score from 20 to 50), "Borderline" (score from 51 to 60), and "Alexithymic" (score $\geq$ 61) (11).

Depressive mood was evaluated with the Beck Depression Inventory (BDI). The BDI, considered a reliable instrument for the evaluation of depression severity in $P D$, is a 21 -item selfrated questionnaire with a four-point Likert response scale (0-3) (14). According to BDI, scores from 0 to 13 represent minimal depressive symptoms, scores of 14 to 19 indicate mild depression, scores of 20 to 28 indicate moderate depression, and scores of 29 to 63 indicate severe depression (15).

Cognitive functions of each participants were assessed with The Mini Mental State Examination (MMSE). MMSE is a tool that can be used to systematically and thoroughly evaluate a mental status. It is an 11-question measure that tests five areas of cognitive function; orientation, registration, attention and calculation, recall, and language. The maximum score is 30. A score of 23 or lower is indicating more severe cognitive problems. The cut point established for the MMSE defines 'normal' cognitive function and is usually set at 24 , although theoretically it could fall anywhere from 1 to 30 .

The severity of IPD was measured with Unified Parkinson's Disease Rating Scale (UPDRS). The UPDRS has been the most used PD scale and the reference measure for regulatory agencies since its development. This scale consists of four subscales. Subscale 1 includes behavior, mentation, and mood. Subscale 2 rates activities of daily living. Subscale 3 (UPDRS III) is a clinician rating of the motor manifestations of PD. Subscale 4 covers complications of therapy. Data for subscales 1, 2, and 4 are elicited from patients and caregivers, whereas data for subscale 3 is examination-based. UPDRS III is an examiner rating of the motor manifestations of PD. This is the most commonly used subscale and has 14 different types of ratings, with many of these ratings done independently for the different limbs. Each of the ratings ranges from 0 to 4 . The total score for subscale 3 ranges from 0 to 108, the sum of scores from 27 observations.

\section{Statistical Analysis}

The collected data were assessed with "SPSS for Windows 17.0". After visual and statistical normal range criteria were tested for suitability; parametric tests were performed. Chi square tests were performed in evaluation of the relationship between categoric variables, and t- test for the evaluation of the differences of the median values of two groups. The data were evaluated as mean and standard deviation. The data in each group were evaluated with Pearson's correlation and $p<0.05$ is accepted as statistically significant.

\section{Results}

This prospective study was conducted on 67 patients with

Table 1. Demographic and Clinical Features of Participants

\begin{tabular}{|c|c|c|c|}
\hline & $\begin{array}{c}\text { IPD } \\
(n=67)\end{array}$ & $\begin{array}{c}\mathrm{HC} \\
(n=70)\end{array}$ & $\begin{array}{l}\text { t-test or other statistics } \\
\text { (specified) }\end{array}$ \\
\hline Demographic Variables & (mean $\pm \mathrm{ss})$ & (mean $\pm \mathrm{ss})$ & \\
\hline Age (years) & $61.20 \pm 9.07$ & $58.32 \pm 4.06$ & 0.821 \\
\hline Education (years) & $9.14 \pm 3.17$ & $10.45 \pm 2.06$ & 1.267 \\
\hline Gender (F/M) & $27 / 40$ & $32 / 38$ & $X^{2}=0.457$ \\
\hline \multicolumn{4}{|l|}{ Clinical measures } \\
\hline Duration of IIIness & $9.56 \pm 3.12$ & - & - \\
\hline BDI & $13.21 \pm 8.17$ & $8.12 \pm 3.46$ & 0.03 \\
\hline Ledd & $1070.33 \pm 295.37$ & - & - \\
\hline Smoked duration ( $\geq 10$ years) & $23.14 \pm 6.75$ & $29.45 \pm 8.23$ & 1.346 \\
\hline UPDRSIII & $32.69 \pm 9.21$ & - & - \\
\hline MMSE & $24.78 \pm 1.09$ & $26.20 \pm 1.08$ & 1.467 \\
\hline TAS-20 & $62.50 \pm 10.72$ & $48.95 \pm 13.28$ & 0.032 \\
\hline
\end{tabular}


IPD (27 women +40 men) and 5 patients with Vascular Parkinsonism (VP) ( 2 women +3 men) and 70 healthy subjects (32 women +38 men). Although there was alexithymia in 4 of 5 patients with VP, it was not taken into consideration because of them being without IPD. Demographic and clinical data of IPD and $\mathrm{HC}$ was demonstrated in Table 1.

Alexithymia total scores ranged from 30 to 72 in the IPD group (median $=62.50$ ) and from 25 to 61 in the HC group (median $=48.95)$. Based on the TAS-20 score, 39 patients with IPD (58.20\%) and $21 \mathrm{HC}(30 \%)$ could be classified as alexithymic; 23 patients with IPD (34.32\%) and $43 \mathrm{HC}(61.42 \%)$ were nonalexithymic, and the remaining 5 patients with IPD $(7.46 \%)$ and $6 \mathrm{HC}(8.57 \%)$ obtained borderline scores.

In the overall group patients with IPD, as well as in the subgroups with or without alexithymia, we explored the possible correlation between TAS-20 and, respectively, the Ledd and duration of illness. TAS- 20 scores were found to be higher in patients with IPD whose disease duration was longer than 8 years and it was no significant correlation was found between TAS-20 total score and Ledd ( $p>0.05)$.

In this study, the relationship of smoking duration longer than 10 years was also explored. Alexithymia was found to be higher in patients who were smokers with IPD group than non-smokers, but it was found to be not statically significant ( $p$ $>0.05$ ).

We also investigated the correlation between the performance on TAS 20 and UPDRS III scores. TAS 20 scores were found to be higher in patients with IPD whose UPDRS III scores were higher than $30(p<0.05)$.

\section{Discussion}

There has been increasing interest in non-motor symptoms of $\mathrm{PD}$, recent studies have investigated the relationship between alexithymia and PD (16). But there are few reports in the literature on alexithymia in patients with $\operatorname{PD}(7,10,12$, $17,18)$. The prevalence of alexithymia in PD patients were indicated about $20-25 \%(10,12)$. In our study alexithymia in IPD patients were found to be $58.20 \%$ as it is higher than previous studies. Second, also as predicted, IPD patients were found significantly more alexithymic than the HC group. In line with our study, Assogna et al (2014) reported that alexithymia occurred twice as often in PD patients compared to HC.

PD is a clinical condition generally characterized by depression and an altered emotional processing (19). The relationship between alexithymia and severity of depression in PD has been studied. In one study which was carried out by Costa (2006) 58 patients were demonstrated a prevalence of $20.7 \%$ of alexithymia and of $20.7 \%$ of major depression. Patients with a diagnosis of major depression were more alexithymic than nondepressed ones. Thus, the authors suggested that the severity of depression might predict alexithymia in PD patients (20). In contrast to Costa et al. (2006), Assogna et al.(2012) suggested that alexithymia is a depression-independent phenomenon in PD patients and may be associated with the disease process (8). This discrepancy might be due to the different setting of the two studies, one evaluating hospitalized patients and the other outpatients and to the methodological differences (16). Up to date studies showed no clear evidence of alexithymia and depression relationship $(17,21)$. Costa et al. (2010) indicated that alexithymia occurred in about $21 \%$ of a cohort of 58 patients with PD and that it was strongly associated with severity of depression. In a similar way with Costa et al.(2010), our findings showed strong relationship between depression and alexithymia.

There are various suggested models about the neurobiological aspect of alexithymia. These studies assert the claim of both the role in miscommunication between corpus callosum and frontal lobe disfunction $(22,23)$. Our high alexithymia scores in patients with $\mathrm{PD}$ patients are in accordance with the neurobiological aspect of the disease. Once again alexithymia was observed higher in 4 of 5 patients with VP but it was not taken into consideration entirely in this study. It may be arising from relationship alexithymia and vascular mechanisms.

We investigated the possible correlation between alexithymia and, respectively, the Ledd, duration of illness and severity of disease. Our findings showed significant correlation between alexithymia and disease duration, and also UPDRS III scores which were higher than 30 . It may be related with a lack of communication between hemispheres and frontal lobe disfunctions as it was mentioned by Larsen et al. (2003) and Meza-Concha et al.(2017). In contrast to our study, Castelli et al. (2014) demonstrated no relationship between alexithymia and disease duration. Also, in this study there was no significant correlation found between alexithymia and Ledd. Similar to our findings Enrici et al (2015) showed no significant correlation between alexithymia and Ledd (24). We also investigated the correlation between the alexithymia and severity of disease. Alexithymia was found higher when UPDRS III scores were $>$ 30. By contrast with our study, Castelli et al.(2014) found no significant correlation between alexithymia and severity of the disease (11). This difference could probably result from differences in patients' characteristics such as dopaminergic treatment dosage etc.

\section{Conclusion}

There were limitations to the present study that need to be acknowledged. Our relatively small sample group may limit generalizability to all patients with IPD, and the neuropsychological measures used to compare IPD and HC groups were limited only to MMSE. Despite the limitations of this study, here we addressed the role of alexithymia in patients with IPD and it is thought that this study will contribute to the literature gap regarding the relationship between alexithymia and IPD. According to the authors, the current study suggests that alexithymia can be one of the non-motor symptoms of IPD and clinicians should consider the alexithymia in patients with IPD evaluation and management. Future studies should better clarify the alexithymia in subtypes of Parkinsonism.

\section{Acknowledgments}

Authorship contributions: Concept: A.R.S., M.C.; Design: A.R.S., M.C; Supervision: A.R.S., M.C; Resources: A.R.S., M.C.; Materials: A.R.S., M.C; Data collection and/or processing: A.R.S., M.C; Analysis and/or interpretation: A.R.S., M.C; Writing: A.R.S., M.C; Critical review: A.R.S., M.C.

\section{Conflict of Interest}

The authors declared they do not have anything to disclose regarding conflict of interest with respect to this manuscript.

\section{References}

1. Dancis A, Cotter VT. Diagnosis and management of cognitive impairment in parkinson's disease. The Journal 
for Nurse Practitioners. 2015;11(3):307-313.

2. Darrow SM, Follette WC.Abehavior analytic interpretation of alexithymia. Journal of contextual behavioral science. 2014;3(2):98-108.

3. Sifneos PE. The prevalence of 'alexithymic'characteristics in psychosomatic patients. J Psychotherapy and psychosomatics. 1973;22(2-6):255-262.

4. Bogdanova $\mathrm{Y}$, Cronin-Golomb A. Alexithymia and apathy in Parkinson's disease: neurocognitive correlates. J Behavioural neurology. 2013;27(4):535-545.

5. Honkalampi K, Hintikka J, Tanskanen A, Lehtonen $J$, Viinamäki $H$. Depression is strongly associated with alexithymia in the general population. Journal of psychosomatic research. 2000;48(1):99-104.

6. Parker JD, Bagby RM, Taylor GJ. Alexithymia and depression: distinct or overlapping constructs? J Comprehensive psychiatry. 1991;32(5):387-394.

7. Poletti M, Frosini D, Pagni C, et al. The association between motor subtypes and alexithymia in de novo Parkinson's disease. Journal of neurology. 2011;258(6):1042-1045.

8. Assogna F, Palmer K, Pontieri FE, et al. Alexithymia is a non-motor symptom of Parkinson disease. $\mathrm{J}$ The American Journal of Geriatric Psychiatry. 2012;20(2):133141.

9. Costa A, Peppe A, Carlesimo GA, Salamone G, Caltagirone C. Prevalence and characteristics of alexithymia in Parkinson's disease. J Psychosomatics. 2010;51(1):22-28.

10. Costa A, Caltagirone C. Alexithymia in Parkinson's disease: a point of view on current evidence. $\mathrm{J}$ Neurodegenerative disease management. 2016;6(3):215-222.

11. Castelli L, Tonello D, Rizzi L, Zibetti M, Lanotte M, Lopiano L. Alexithymia in patients with Parkinson's disease treated with DBS of the subthalamic nucleus: a casecontrol study. J Frontiers in psychology. 2014;5:1168.

12. Assogna F, Palmer K, Pontieri FE, et al. Alexithymia is a non-motor symptom of Parkinson disease. The American Journal of Geriatric Psychiatry. 2012;20(2):133-141.

13. Güleç $H$, Köse $S$, Güleç $M$, et al. Yirmi soruluk Toronto aleksimi ölçeğinin Türkçe uyarlamasının geçerlik ve güvenirliğinin incelenmesi. J Klin Psikofarmakol Bul. 2009;19:214-220.

14. Hisli N. Beck depresyon envanterinin universite ogrencileri icin gecerliligi, guvenilirligi.(A reliability and validity study of Beck Depression Inventory in a university student sample). J Psychol. 1989;7:3-13.

15. Salkind M. Beck depression inventory in general practice. J The Journal of the Royal College of General Practitioners. 1969;18(88):267.

16. Ricciardi L, Demartini B, Fotopoulou A, Edwards MJ. Alexithymia in neurological disease: a review. J The Journal of neuropsychiatry clinical neurosciences. 2015;27(3):179-187.
17. Goerlich-Dobre KS, Probst C, Winter L, et al. Alexithymiaan independent risk factor for impulsive-compulsive disorders in Parkinson's disease. J Movement Disorders. 2014;29(2):214-220.

18. Assogna F, Cravello L, Orfei MD, Cellupica N, Caltagirone C, Spalletta G. Alexithymia in Parkinson's disease: a systematic review of the literature. J Parkinsonism and related disorders. 2016;28:1-11.

19. Péron J, Dondaine T, Le Jeune F, Grandjean D, Vérin M. Emotional processing in Parkinson's disease: a systematic review. J Movement Disorders. 2012;27(2):186-199.

20. Costa A, Peppe A, Carlesimo G, Pasqualetti P, Caltagirone C. Alexithymia in Parkinson's disease is related to severity of depressive symptoms. J European journal of neurology. 2006;13(8):836-841.

21. Nezhad SR, Rad MM, Farrokhi N, Viesy F, Ghahari S. The relationship of alexithymia with depression, anxiety, stress, and fatigue among people under addiction treatment. J Annals of Tropical Medicine Public Health Monograph. 2017;10(6):1698.

22. Larsen JK, Brand N, Bermond B, Hijman R. Cognitive and emotional characteristics of alexithymia: a review of neurobiological studies. J Journal of psychosomatic research. 2003;54(6):533-541.

23. Meza-Concha N, Arancibia M, Salas F, et al. Towards a neurobiological understanding of alexithymia. J Medwave. 2017;17(4):e6960-e.

24. Enrici I, Adenzato M, Ardito RB, et al. Emotion processing in Parkinson's disease: a three-level study on recognition, representation, and regulation. J PLoS One. 2015;10(6):e0131470. 